\title{
O crime politico
}

Prelecção inaugural do curso juridico á $10^{\circ}$ de Abril de 1930 pelo Dr. CANDIDO MOTTA, (Prof. Cathedratico de direito Penal)

Meus caros Mestres.

Jovens Amigos.

Quiz a sorte, para não dizer a fatalidade, que a mim coubesse a honra de inaugurar o anno lectivo de 1930 no dia de hoje.

Infelizmente tal distincção não me coube por ser o mais sabio desta Casa, mas pura e simplesmente, por ser o mais antigo. Podeis, porém, ficar inteiramente tranquillos: não vos impingirei um indigesto "poisson d'avril" E, se o que vou vos dizer não fôr a rigorosa expressão da verdade scientifica, a culpa não me cabe; mas aos autores em quem, ha 33 annos, me tenho inspirado, alimentando o meu espirito, e cujos ensinamentos tenho, por minha vez, procurado transmittir a tantas gerações academicas, que tem ornado, dado vida e alegria a estas já seculares arcadas.

Vou tratar da primeira these do nosso programma do corrente anno, isto é, da parte especial do nosso Cod. Penal, que se inscreve: "Do crime politico, definição, natureza, historia, limites segundo as doutrinas antigas e modernas: classificação" 
Considerados sob o ponto de vista da sua natureza intrinseca, os crimes dividem-se em politicos, militares e communs.

Crimes politicos são aquelles que offendem sómente a ordem politica do Estado, quer seja esta externa, como a independencia da Nação, a integridade territorial as relações entre duas ou mais nações; quer seja interna, como a fórma de governo, a organisação e o funccionamento dos poderes politicos e dos direitos politicos dos cidadãos.

Os crimes politicos se distinguem dos crimes communs pela natureza do direito violado, pelos moveis aos quaes obedece o agente e pelo fim que elle tem em vista.

Os crimes politicos foram, por muito tempo, considerados como os mais graves e perigosos porque, ao passo que os crimes communs não affectam, em geral, senão direitos individuaes, os crimes politicos põem em perigo o Estado e podem produzir a subversão e a ruina de todo o paiz. Assim eram elles punidos, sob o nome de crimes de "lesamagestade", com o maximo rigor, com penas excepcionaes e submettidos ao conhecimento de tribunaes igualmente excepcionaes.

Este modo de encarar a criminalidade politica cessou depois da revolução de 1830 , na França. O governo de Luiz Felippe, separando nitidamente os crimes politicos dos crimes communs, estabeleceu para os primeiros uma escala de penas especiaes mais brandas que as penas ordinarias, e firmou nos tratados internacionaes o principio da não extradicção e do direito de asylo em materia politica; principio este que se tornou uma regra geral nas relações internacionaes de todas as nações civilisadas.

Esse contraste absoluto no tratamento dos delinquentes politicos foi devido á interpretação do caracter e do papel que o crime politico assumia ou assume na evolução da humanidade.

Ao passo que outr'óra o criminoso politico era considerado como um inimigo publico, modernamente, em certos crimes, é encarado como um homem de progresso, de- 
sejoso de melhorar as instituições politicas do seu paiz, tendo as intenções as mais louvaveis, abrindo a marcha na vanguarda da humanidade; sendo apenas censuravel porque quer chegar muito depressa, empregando meios irregulares, illegaes e violentos para a realisação dos seus ideaes.

$\mathrm{Si}$, sob este ponto de vista, elle deve ser punido no interesse da ordem estabelecida, a sua criminalidade jamais poderá ser comparada á do malfeitor ou criminoso commum, do ladrão ou do assassino, etc.

A criminalidade politica não tem a mesma immoralidade. Ella é relativa, dependendo dos tempos, dos logares, das circumstancias, das instituições do paiz; sendo muitas vezes, como já disse, inspirada por nobres sentimentos, por moveis desinteressados, por idéas de progresso.

$O$ autor do crime politico é antes um vencido do que um criminoso; tanto que pode tornar-se, depois da victoria da sua causa, um administrador do paiz e o arbitro dos seus destinos.

A reacção penal contra elle exercida não é, nem deve ser, da mesma natureza que a exercida contra o ataque ás condições immanentes da existencia humana; é antes uma obra de defesa de um partido politico contra um ataque a uma organisação e a um regimen historicamente transitorio.

A relatividade do crime politico está em que os seus autores só são considerados criminosos quando vencidos; quando são, porém, vencedores, se tornam até heróes.

Já o insigne R. Garofalo dizia, na "Nuova Antologia" de Maio e Junho de 1928, tratando da criminalidade e da amnistia na Italia:

"Ora è naturale che si il tentato rivolgimento politico abia successo, gli autori dei fatti che a questo abbiano concorso sarano dal nuovo Governo considerati come meritevoli di premio, non di pene" 
Se a 15 de Novembro de 1889 nós, os republicanos, fossemos vencidos, seriamos criminosos; mas vencedores constituimos a ordem legal do paiz.

Entretanto, em nossos dias, fez-se uma reacção contra a extensão do crime politico e do direito de refugio: $1 .^{\circ}$ ) para os delictos chamados sociaes ou contra a humanidade; isto é, delictos, não contra um systema politico de um determinado Estado ou contra tal ou qual forma de governo mas contra as bases de toda organisação social como sejam as conspirações anarchistas ou nihilistas; $20^{\circ}$ ) para os crimes de traição contra a nação e a patria, com o fim especial de applicar a esses criminosos a pena de morte, mesmo naquelles paizes em que foi ella abolida.

O notavel criminalista Lours Proal, depois de passar em revista, na sua interessante "La criminalité politique", o machiavelismo, o assassinato politico, o tyranicidio, a anarchia, os odios politicos, as espoliações politicas, a corrupção dos homens politicos, a corrupção eleitoral, das leis e da justiça, dos costumes publicos, chega ás seguintes conclusões, que tambem adopto:

“A politica se deshonrou pelo emprego de meios reprovaveis e adopção de maximas immoraes. Ella precisa se rehabilitar moralisando-se. Depois de ter por largo tempo praticado a velhacaria, a mentira, a intriga e a violencia, ella deveria, ao menos por novidade, experimentar um pouco de lealdade, tolerancia e justiça. Hoje, mais que nunca, gosta-se de novidades. Ora, que de mais novo que uma politica moral? Talvez que assim se chegasse a reconhecer que, na vida publica como na particular, a probidade é a maior das forças e a suprema habilidade.

O machiavelismo não deve ser somente detestado pelos homens de bem; deve ainda ser considerado como funesto aos verdadeiros interesses da nação.

Não ha grande politica immoral. A astucia e a violencia podem fazer alcançar successos ephemeros, mas não assegura a grandeza e a prosperidade de um paiz. 
Os successos da politica immoral não duram: cedo ou tarde tanto as nações como os individuos, os politicos como os simples particulares serão punidos pelo mal ou recompensados pelo bem que fizeram.

O crime politico é mais frequentemente punido do que se acredita. Os que fazem perecer os seus adversarios soffrem muitas vezes a mesma sorte.

Ha mais immoralidade que profundeza no "machiavelismo" A politica tortuosa e violenta não era a de S. Louis, de l'Hopital, de Henrigue iv, de Sully, de Turgot, de FranKLIN e de Washington.

Seu exemplo prova que se póde ser um grande rei, um grande ministro, um grande cidadão e, ao mesmo tempo, um homem bom em toda a extensão da palavra.

Genios poderosos, ao contrario, perderam os povos que governavam, porque despresaram a justiça e não executaram mais do que os calculos da politica machiavelica.

Napoleão I.o, que só se inspirava na "razão d'Estado", acabou por perder a razão fazendo a guerra da Hespanha e a campanha da Russia.

Danton e Robespierre, aos quaes não faltava talento perderam a Republica querendo salval-a pelo terror.

A liberdade não se impõe pela guilhotina; a fraternidade não se estabelece pelo exterminio dos adversarios; o reino da justiça e da egualdade não se funda pelo massacre popular ou pelo massacre judiciario.

Os discipulos de Machiavel dizem que a politica deve, si fôr preciso, praticar violencias e mesmo crimes para salvar o povo; mas o que elles chamam "salvação do povo" não é, muitas vezes, mais do que a salvação do seu predominio delles. Os autores do 18 Fructidor, que deram o golpe d'Estado sob o pretexto de salvar a Republica, só violaram as leis para escapar a um perigo pessoal e, longe de salvar a Republica, fazendo appello a um general, crearam um precedente para o 18 Brumario.

A salvação publica é um pretexto para todas as violencias e iniquidades. Além d'isso, quando um crime po- 
litico é realmente commettido para a salvação do povo, nada prova que este crime fosse necessario e que o povo não pudesse ser salvo por outros meios.

A salvação do povo está antes no respeito do direito do que na sua violação. Um povo que cumpre o seu dever póde aguardar o futuro com confiança.

Si elle soffre momentaneamente pela justiça, é bem raro que o dia da reparação não chegue por sua vez: porque tanto para as nações como para os individuos são as virtudes que os elevam e os vicios que os abatem.

A politica machiavelica não é a grande politica; não é necessario um genio para pratical-a. E' mais facil governar com expedientes do que com principios. Além d'isso esta politica não tem mais razão de ser nas sociedades modernas.

Comprehende-se realmente que o principe de Machiavel, isto é, um soberano absoluto tenha interesse em semear a discordia entre os seus subditos afim de melhor dominal-os. Mas a maxima “dividir para reinar" não póde convir a um governo livre que se apoia na opinião e que tem por isso justamente o maior empenho em unir todos os cidadãos.

$O$ terror póde ser um instrumento de governo para um dictador popular ou militar, mas não póde ter applicação em um governo de opinião.

E' sobretudo com o progresso da razão publica que é preciso contar para tornar a politica mais leal e mais justa. Os homens politicos, as assembléas e os soberanos, sabendo que serão arrastados ao tribunal da opinião, que lhes pedirá contas severas da sua conducta, tornar-se-ão mais circumspectos no emprego dos meios que despertam a indignação publica.

A politica não tem por fim unicamente a manutenção da ordem e a protecção dos interesses materiaes; ella procura tambem educar. Não se governam os homens somente pelo interesse e pela força, mas pelas idéas e sentimentos. Um sentimento elevado não prejudica a politica. Os 
grandes progressos politicos não foram mais do que progressos philosophicos, uma applicação da philosophia christã.

Como a vida humana, a politica deve ser espiritualisada, se não quizer cahir e chafurdar-se na lama. A mudança do pessoal politico será insufficiente se não fôr acompanhada de uma reforma moral. De facto, se o novo pessoal tiver a mesma falta de principios que o antigo, não se terá feito mais do que substituir vaccas gordas por vaccas magras, que, por sua vez, tratarão de engordar. Entre os scepticos gordos e os magros a differença é pequena: e se alguma existe é em favor dos primeiros.

$\mathrm{Na}$ realidade os scepticos cheios são menos perigosos que os esfomeados, porque se poderá esperar que, tendo arranjado os seus negocios, tratem afinal dos do paiz. Aos que indicavam ao nosso grande FeIJó, o nome de um certo politico para Ministro da Fazenda da Regencia dizia elle admirado: "Como quereis que eu nomeie para esse posto um homem cuja reputação é das mais duvidosas"?

"Sim; responderam-lhe, elle realmente furta, o que é um mal; mas ao menos evita um perigo maior não deixando, zeloso como é, que outros furtem"

E' o que, segundo Sarnt-Srmon, dizia cynicamente o superintendente Maison, quando the retiraram as finanças: "Fizeram mal; porque arranjei os meus negocios, mas ia agora arranjar os delles"

A regressão aos principios e ás crenças moraes, a substituição dos appetites pelas idéas e pelos principios salutares do direito é, pois, o verdadeiro remedio contra a corrupção politica.

Os homens d'Estado evitariam muitas faltas politicas se respeitassem mais a justiça. Suas faltas politicas são muitas vezes faltas moraes; á medida que se afastam do direito se afastam do bom senso, da habilidade; entregamse a paixões que perturbam a sua intelligencia. As idéas justas, as resoluções prudentes são inspiradas por uma consciencia recta. Procurando a moral, a politica evitará duas graves molestias, que surgiram do excesso de sophis- 
mas e do desencadeamento das paixões - a loucura socialista e o furor anarchista.

O remedio para evitar tudo isso não é difficil: basta restabelecer no espirito publico e na educação da mocidade o sentimento do dever e da responsabilidade pessoal; basta combater os sophismas que conduzem á absorção do individuo pelo Estado e querem fazer de cada cidadão uma peça de machina colossal, produzindo a riqueza e distribuindo-a segundo as necessidades.

O verdadeiro remedio á crise consiste na regressão á velha moral que ensina que tanto os operarios como os patrões são feitos para o dever, o trabalho e a responsabilidade.

Com que outra doutrina se poderia ensinar aos ricos o espirito de sacrificio, o abandono voluntario do superfluo; e aos pobres, a obrigação do esforço pessoal, os meritos da paciencia, a confiança no futuro, o respeito ao direito?

Os delictos politicos se dividem em duas grandes categorias: os puramente politicos e os relativamente politicos.

Entre as muitas definições do delicto puramente politico a que me parece melhor é a seguinte: "a violação dos direitos que pertencem ao Estado considerado como poder politico, tanto no interior como no exterior"

Quando o delicto lesa ao mesmo tempo os direitos do Estado e os dos individuos é um "delicto concurrente" ou delicto politico relativo, complexo e connexo"

A ordem politica contra a qual é dirigido o delicto, e que serve para o caracterisar, comprehende, no exterior, a independencia da nação, a integridade territorial e as relações de Estado a Estado; no interior a forma de governo, o funccionamento dos poderes politicos, o livre exercicio dos direitos dos cidadãos, as fraudes eleitoraes, comprehendidas nos arts. 87 a 116 do nosso Cod. Penal. 
E' preciso, porém, sob este ponto de vista, distinguir claramente a administração do paiz, que não tem caracter politico e o governo do paiz com os seus diversos orgams; os poderes politicos encarregados do governo dos interesses geraes do paiz e os poderes publicos encarregados de applicar aos interesses individuaes as medidas geraes tomadas pelos poderes politicos, ou não tendo mais que a gestão dos interesses puramente locaes ou municipaes.

$\mathrm{O}$ ataque á existencia e aos actos dos poderes publicos constitue um "delicto politico" O ataque á existencia dos poderes publicos é um delicto politico porque é dirigido contra uma instituição creada pelos poderes politicos; ao contrario, o ataque dirigido aos actos dos poderes publicos não tem esse caracter politico. Assim, por exemplo, a violação dos direitos dos representantes do povo no Congresso Nacional; a violação das immunidades do deputado ou senador; todo aquelle ataque que tem por fim impedir que os poderes constitucionaes do paiz exerçam a sua acção funccional regularmente; o acto pelo qual se impede o cidadão de exercer o seu direito de voto. São estes ataques de natureza politica porque são dirigidos contra instituições creadas pelos poderes politicos da Nação.

A desobediencia a uma determinação de autoridade administrativa não é delicto politico - é delicto commum. Na primeira hypothese o acto affecta a collectividade; na segunda é uma violação á ordem de uma autoridade; não tem caracter politico; pertence simplesmente ao ramo administrativo.

Entende-se por delictos politicos "relativos" aquelles que, sob o ponto de vista objectivo, lesam o individuo ou o Estado, considerado como pessoa privada; mas que sob o ponto de vista subjectivo, na intenção dos seus autores, têm como movel, como pretexto, como fim - a politica.

Os delictos politicos relativos podem ser "complexos a connexos" Ha delicto complexo quando o facto delictuoso, sob o ponto de vista material, lesa ao mesmo tempo a ordem politica e o interesse privado. 0 typo desse delicto 
é o assassinato do Chefe do Estado, é o "regicidio", expressão que, em Direito Penal, comprehende todos os attentados contra a vida dos Chefes d'Estado ou melhor, como diz Em. Regis: “A palavra regicida é empregada, na falta de uma expressão mais exacta, para designar os fanaticos que, alheios á qualquer seita ou a qualquer conjuração, têm assassinado ou tentado contra a vida de um monarcha ou poderoso do dia"

Exemplo do primeiro caso temos no crime do Buiça, que matou o rei D. Carlos de Portugal e o Principe D. Luiz, herdeiro do throno; no de Caserio Santo apunhalando traiçoeiramente o bondoso Sadi-Carnot, presidente da Republica Francesa; criminoso este, sobre cuja personalidade se abrio um sabio e interessante debate entre os notaveis scientistas A. Bournet, Lacassagne e Regis.

Caracterisa o segundo, Manços de Paiva matando covardemente o prestigioso brasileiro senador Pinheiro $\mathrm{MA}_{\mathrm{A}}$ CHADO, que tinha em mãos a direcção suprema da politica nacional; e ainda mais recentemente, isto é, a 28 de Junho de 1914 o grande e terrivel acontecimento: o assassinato do principe herdeiro da Austria, o Archi-duque Francisco Fernando e sua mulher a duqueza de Hohenberg, nas ruas de Sarajevo, faisca formidavel que ateou a guerra mundial, e pela qual responderam: Ilie Valjko, Cubrilovic, Niedo Kerovic, Jowanovic e Milovic, condemnados á forca: Mitar Kerovic á prisão perpetua; Gravilo Princip, Cabrinovic e Grabez a 20 annos; Vaso Cubrilovic a 16 annos; Popovic a 13 annos; Kranjcevic e Gjukic a 10 annos; Stjepanovic a 7 annos, Zagorac e Perin a 3 annos.

Ha ainda delicto complexo quando, n'um movimento revolucionario, os agentes atacam um armazem, um deposito de armas e dellas se apoderam bem como das respectivas munições. Ha delicto "connexo" no caso em que ha muitos factos delictuosos, ligando-se uns aos outros por um laço mais ou menos estreito, violando os direitos individuaes com um fim politico. Exemplo: os revolucionarios para derribar o governo apoderam-se dos arsenaes, das 
uzinas, destroem as propriedades publicas ou privadas; matam em combate os membros do partido opposto.

A simples concurrencia do tempo é insufficiente para dar a estes delictos o caracter politico-relativo. E' preciso tambem que os seus autores tenham, ao realisal-o, obedecido a moveis politicos e tido a intenção de attingir um fim egualmente politico. $O$ nosso Codigo não fala nem define o que seja crime politico; todavia a natureza dos factos criminosos comprehendidos nos artigos 86 a 123 é d'aquellas que, segundo os principios universalmente acceitos, acompanham os delictos politicos e são, por isso, considerados como taes. A unica referencia positiva que temos na nossa legislação sobre os delictos politicos, ou as unicas referencias, são as da Constituição Federal, art. 60, alinea i, que dá competencia aos tribunaes federaes para o processo e julgamento dos crimes politicos sem enumerar quaes sejam; e o art. 15, $i$, do Dec. n. 848 de 11 de outubro de 1890, que deu organisação á justiça federal.

Temos tambem a considerar como delictos politicos, á vista dessas disposições, as violações dos arts. 47 a 55 da Lei n. 35 de 26 de Janeiro de 1892, que foi a que estabeleceu o primeiro processo para as eleições federaes.

A doutrina consagrada pela nossa jurisprudencia provocada pelo attentado de 5 de Novembro de 1897, dirigido contra a pessoa do inesquecivel patricio, o dr. Prudente dr: Moraes e em que, ao lado do general Mendes de Moraes, gravemente ferido, succumbio o bravo e valente Marechal Machado Bittencourt, Ministro da Guerra, é a seguinte, e que está de accordo com os principios já conhecidos: o attentado contra a vida do Chefe da Nação em occasião diversa d'aquella em que se acha exercendo qualquer das attribuições constitucionaes, taxativamente declaradas no art. 48 e $\S \S$ da Const. Federal, não é crime politico.

A consequencia é que só é considerado crime politico o attentado contra a vida do chefe da Nação no momento em que está exercendo qualquer das suas attribuições constitucionaes. Embora seja politico o movel do attenta- 
do, não basta, entretanto, para dar natureza politica ao mesmo, por isso que o movel só qualifica o crime quando constitue o dólo especifico da sua respectiva definição legal. Sómente por analogia ou paridade, o que é prohibido pelo nosso Codigo, poder-se-ia capitular o attentado contra o presidente da Republica nos artigos do Codigo relativos aos crimes contra o livre exercicio das attribuições constitucionaes do poder executivo; e, se assim fosse, teriamos o absurdo de que os attentados contra a vida do Chefe do Estado seriam punidos com outras penas que não as applicadas aos attentados á vida de qualquer pessoa, e, assim, quem attentasse contra a vida do Chefe da Nação teria pena maxima de 6 annos de prisão cellular; ao passo que quem praticar um homicidio contra um simples particular terá uma pena maxima de 30 annos. Foi por isso que, segundo a jurisprudencia provocada pelo attentado de 5 de Novembro e firmado pelo Supremo Tribunal Federal, ficou adoptado o principio consagrado pela doutrina corrente e pelos diversos tratados de extradição, considerando como delicto commum o attentado contra a vida do Chefe da Nação, afim de não ficar este em posição inferior a qualquer individuo.

E', como se vê, uma solução accomodaticia, bem justificada, mas que aberra dos verdadeiros principios scientificos e que deve, sem inconveniente, ser modificada.

Não será crime poltico o assassinato de um Chefe de Governo licenceado, fóra da séde governamental, quando o fim do agente era justamente impedir o seu regresso e a sua reintegração no cargo?

A Anthropologia criminal, e a Psychiatria tem, como se sabe, pontos de contacto numerosos e, talvez, não haja questões mais interessantes que as que dizem respeito, ao mesmo tempo, a estes dois ramos da sciencia, lhes servindo de traço de união e esclarecendo por assim dizer uma pela outra.

O estudo dos regicidas é deste numero, porque póde ser encarado quer sob o ponto de vista dos dados anthropolo- 
gicos, quer sob o ponto de vista da clinica propriamente dita.

Anthropologicamente, este estudo foi emprehendido ou pelo menos esboçado pelo advogado Laschi que, no primeiro Congresso de Roma, em 1885, lhes consagrou algumas paginas do seu interessante relatorio sobre o delicto politico.

Clinicamente não foi elle abordado; apenas delle foi feita menção de modo incidente em alguns autores entre os quaes Brierre de Boismont e Cullerre.

Regrs tratou de proseguir no terreno medico-psychologico, e depois de tres annos de investigações pôde reunir um grande numero de documentos relativos a mais de oitenta fanaticos celebres.

LASCHI, em sua memoria, dividiu os regicidas em tres categorias :

1..$^{\circ}$ Os loucos, cuja excitação para o crime reside o mais frequentemente nas allucinações que escrupulos religiosos ou um fanatismo sectario despertam no espirito enfermo, como por exemplo Jean Chatel, Jacques Clement, Ravaillac, Poltrot, Damien.

2..$^{\circ}$ Os regicidas mattoïdes, impellidós ao delirio por uma extrema vaidade, pelo desejo de fazer falarem a seu respeito, de conquistar celebridade, como Guiteau e Passanante.

3.') Os regicidas por paixão, isentos de quaesquer anormalidades psychicas, movidos por um sentimento elevado de independencia, um nobre altruismo e exasperação causada por desastres nacionaes, os exemplos gloriosos da historia, e muitas vezes tambem pelo presentimento de liberdades que a humanidade espera do futuro, taes como Carlota Corday, Vera Sassulitch, Salowief.

Esta divisão, comquanto racional na apparencia, é em demasia psychologica para ser inteiramente exacta; e é aqui que só a clinica offerece verdadeiro terreno de apoio. 
Encarando os regicidas sob este aspecto, quer com auxilio de documentos da historia, quer pela observação hodierna, percebe-se que individualidades multiplas e perfeitamente distinctas são confundidas sob esta denominação.

Antes de tudo convem separar nitidamente os verdadeiros dos falsos regicidas.

Os verdadeiros regicidas são aquelles nos quaes o attentado contra uma personalidade de nota foi a consequencia directa e forçáda d'um estado de espirito particular. Os falsos regicidas, ao contrario, são aquelles nos quaes o attentado, de resto mais apparente que real, foi pura e simplesmente a obra do acaso, sem connexão immediata com o fundo das idéas, delirantes ou não.

$\mathrm{Na}$ primeira categoria encontram-se Poltrot que ferio mortalmente o duque de Guize para tirar deste mundo um inimigo jurado dos Santos Evangelhos e ganhar assim o paraizo; Balthasar Gerard, matando Guilherme de Nassau para ser um athleta generoso da egreja romana e tornarse bemaventurado e martyr; Ravaillac que assassinou Henrique IV para o impedir de fazer a guerra ao Papa e transferir a Santa Sé para Paris; Damiens que ferio Luiz $\mathrm{XV}$ com o canivete para o avisar de que devia repôr todas as cousas no seu logar e restabelecer a tranquillidade nos seus Estados; Henrique l'Admiral e Carlota Corday que atacaram Collot d'Herbois e Marat para salvar a Republica; Aimée Cecile Renault procurando atacar Robespierre para provocar a volta do rei, pelo sacrificio da sua vida; Paris l'Ainé, apunhalando Lepelletier Saint-Fargeau para vingar a morte de Luiz XVI; Fred. Staaps pretendendo matar Napoleão $10^{\circ}$ para obedecer a uma inspiração divina e restituir a paz ao mundo; Louvel assassinando o Duque ide Berry com a idéa de livrar successivamente a França de todos os Bourbons; Alibaud atirando sobre Luiz Felippe para fazer cessar um reinado de sangue: o abbade Verger immolando o Arcebispo de Paris para protestar contra o Dogma da Immaculada Conceição; Orsini tentando fazer desapparecer Napoleão $3 .^{\circ}$, o amigo do Papa e o adversario 
da Italia; Hoedel e Nobiting descarregando as suas armas sobre o imperador Guilherme, no interesse da Allemanha e do socialismo; Guiteau matando o presidente Garnfield "por necessidade politica e pressão divina"; Passanante precipitando-se com uma bandeira socialista em punho sobre o rei Humberto a quem quiz matar para fundar a Republica Universal; Hillairaud attentando contra a vida de $\mathrm{Ba}-$ zaine para cumprir um juramento solemne e vingar por ordem de Deus a sua patria; Aubertin atirando sobre J. Ferry para supprimir o máo genio da França; Gasnier querendo matar uma pessoa qualquer da embaixada allemã para fazer rebentar uma guerra que, graças a elle, terminaria pelo restabelecimento do commercio, etc. etc.

Na segunda categoria citam-se Mariotti e Perrin atirando ambos de pistola contra a carruagem de chefes de governo, não para matar, pois que um fez pontaria para o chão e o outro só tinha a sua arma carregada de polvora; mas para attrahir a attenção sobre elles e chegar assim a obter justiça contra offensas mais ou menos imaginarias. Os primeiros queriam destruir um personagem importante e tudo nelles convergia para esta idéa; os outros, erguendo-se em face de homens de destaque a quem na realidade não desejavam mal algum, buscavam unicamente reivindicações pessoaes. Nos primeiros o regicidio era o fim, nos segundos - o meio.

Como se vê só os individuos da primeira categoria merecem o nome de regicidas e, por conseguinte, sómente elles é que devem ser o objecto das nossas observações. Quanto aos outros são, em geral, alienados communs, na maior parte affectados de mania de perseguição, ou pertencentes á categoria desses insensatos que matam o primeiro que encontram na rua ou fazem um escandalo em reuniões selectas para passar um grande dia no jury e alli pleitearem um processo de que até então ninguem tinha ouvido falar.

E' por um mesmo processo psychologico que se produzem successivamente n'estes individuos as idéas de per- 
seguição, a perseguição de males imaginarios por meio de reclamações sem numero ás altas autoridades; o arrastamento irreflectido mas fatal para um acto criminoso destinado, segundo as suas proprias expressões, a attrahir a attenção sobre elles e a obrigar a lhes fazer justiça.

Tal é o falso regicida; eis-nos agora em face dos verdadeiros. Ainda aqui é necessario uma importante distinção preliminar. Entre os individuos que matam um grande personagem ha, com effeito, alguns que são absolutamente loucos e que agem como taes. Tal, por exemplo, Margaret Nicholson, affectado de megalomania e ferindo o rei George III, em 1786, porque a corôa era sua, e que, se não lhe restituissem o direito, a Inglaterra se veria afogada em sangue durante cem gerações.

Tal ainda Carlota Carlemigelix ou Aspasia Mizelli, tratada como louca na Salpetrière e d'alli sahindo não curada, que, no $1 .^{\circ}$ de prarial, anno III, impellida unicamente pelo seu delirio, fere o deputado Feraud com um golpe de sabre, o acaba de matar com os tacões dos sapatos e tenta fazer o mesmo aos deputados Camboulas e Boissy d'Anglas.

Tal tambem Anna Neil, que tendo enlouquecido pela perda de uma propriedade, o que ella attribuia ao presidente Johnson, quiz matal-o para se vingar.

Tal, emfim, Roderich Maclean dando, a 2 de Março de 1882 um tiro de pistola contra a rainha Victoria, porque o povo inglez era seu inimigo; porque ella não cessava de vestir-se de azul só para o aborrecer; e porque lhe recusavam uma carta de admissão n'uma casa de saude.

Temos ahi regicidas de verdade, mas regicidas de occasião, mais loucos, em fundo, do que regicidas.

Eis porque podem se encontrar entre elles todos os typos de alienados, a começar do vesanico puro até os epilepticos agindo sob a influencia de allucinações ou de suas impulsões inconscientes.

Qualquer que seja mesmo a forma da sua loucura, ella não se afasta do aspecto ordinario e não tem um traço distinctivo. Alguns são delirantes nos quaes o acto morbido 
se dirigiu accidentalmente contra um monarcha ou um poderoso do dia, mas que obdeceram aos mesmos moveis que os seus congeneres. Fóra o facto do seu attentado, que os torna subitamente celebres, não offerecem como enfermos interesse especial.

Inteiramente diversa e a ultima categoria de regicidas, que constitue uma classe verdadeiramente a parte e merece um estudo particular. Os individuos de que ella se compõe são os regicidas puros, os regicidas-natos ou de temperamento; e as analogias que os approximam são taes que não existe differença alguma assignalada na maneira de ser e de agir, tanto nos de hoje como nos de outr'ora. Analysando-os de perto percebe-se que pertencem, por assim dizer, á mesma familia e, segundo a justa expressão de Morel, são realmente irmãos pathologicos.

Que se deve fazer dos regicidas?

Outr'ora, e apezar da idéa vaga que se tinha da sua loucura, eram condemnados ao mais terrivel supplicio, isto é, o dos parricidas; não só com o fim de os castigar como tambem para servir de exemplo.

Em épocas mais recentes, os reis foram tentados por diversas vezes, a usar de indulgencia, á vista do estado de espirito dos criminosos.

Conta Michelet que Luiz XV teve, por um momento, a idéa de mandar prender Damien; Napoleão $10^{\circ}$ quiz perdoar Staaps; Luiz Felippe, Alibasd; Napoleão $3 .^{\circ}$, a Oruini; mas a entourage militar se oppoz allegando a necessidade de conter pelo exemplo as disposições dos exaltados.

Quanto aos regicidas mais recentes, Oliva, Otero, Passanante, Guiteau, Galeote, Hillairaud, foram, a despeito da perturbação do seu espirito, condemnados a penas mais ou menos severas. E' verdade que os proprios medicos, en- 
ganados por sua apparente lucidez, e influenciados, talvez, pela natureza do attentado, sempre se mostraram em desaccordo, e hesitaram em declaral-os alienados: não vendo que se tratava de seres á parte, cujo verdadeiro caracter e verdadeiro lugar no quadro pathologico não podiam ser determinados e apreciados senão por um estudo comparativo e aprofundado de uns com os outros.

Depois disso, que ha de admirar si, apesar dos eloquentes protestos dos defensores, os juizes applicaram a esses in felizes toda a severidade das leis e si os proprios monarchas foram impotentes para perdoal-os?

A sciencia e a humanidade abdicando os seus direitos, só resta a razão d'Estado, essa cousa cega e implacavel diante da qual tudo deve ceder e desapparecer.

Sem ella, Oliva teria sido, sem duvida alguma, perdoado. "Ter-se-ia visto com satisfacção, em todas as espheras da sociedade hespanhola, um indulto real; mas parece que Canovas del Castillo fez prevalecer a razão d'Estado junto ao jovem Monarcha, e que as repugnancias deste foram vencidas pela consideração que invocava o mesmo Ministro. O principal argumento de Canovas era que o imperador Guilherme não tinha perdoado a Hoedel, e que, por esse motivo, um indulto poderia parecer a certos olhos como uma indirecta censura dirigida ao poderoso soberano allemão".

Em relação a Otero, as mesmas difficuldades. A Rainha e a princeza das Asturias instaram para obter do rei o seu perdão, mas o Gabinete teve que obedecer á razão d'Estado e á consideração de politica estrangeira.

$\mathrm{E}$ eis como doentes taes como Oliva, Otero, Passanante, Guiteau, Hillairaud e Galeote foram condemnados por um attentado de que, certamente, não eram responsaveis!

Si esta affirmação parece aventurosa, si apesar das numerosas provas clinicas da perturbação mental dos regicidas fosse possivel conservar ainda alguma duvida, um ultimo facto bastaria para dissipar todas as duvidas, e é o seguinte: a maior parte dos regicidas tem, como se sabe, 
pago com a propria vida a sua impulsão morbida, e bem poucos têm escapado á morte infamante dos criminosos.

Ora, que fim tiveram estes tristes privilegiados? La Sahla, após duas abortadas tentativas de regicidio, atira-se n'agua em um accesso de delirio e acaba os seus dias no hospital, atacado de febre ataxica lenta, nervosa, isto é, de affecção mental bem caracterisada. Galeote, logo após a sua condemnação, tem a sua loucura transformada em verdadeiro furor. "Elle tem, diz o jornal da época, ataques de nervos quasi constantes. Solta gritos terriveis. Canta e prega durante grande parte do dia. Quando se julga interrompido pelo auditorio a quem discursa de cima de uma mesa, grita: "Deixae-me explicar a palavra divina, não me interrompais". Quando está exhausto, não podendo mais falar cae n'uma lethargia de curta duração e recomeça a arenga. Seu estado tornou-se de tal modo claro que foi internado afinal n'um asylo de alienados.

Que foi Passanante depois de dez annos? Dil-o o Dr. Virgilio d'um modo tão preciso quão eloquente: "Por uma estranha e singular contradição, de regenerador do mundo que elle se julgava, cahiu na mais sombria e degradante demencia. Segundo o que me contaram testemunhas presenciaes, foi em vão que se procurou em sua fronte o brilhar de um pensamento; elle é indifferente á sua posição actual: sem necessidades, sem vontade, sem esperança, sem affeição, sem soffrimento. Ha mais: perdeu todo sentimento de pudor e de personalidade, e, finalmente até a simples idéa instictiva da escolha da sua alimentação: elle amassa e come os seus proprios escrementos!

Eis no que dão os regicidas quando sobrevivem!

Repito: que se deve fazer dos regicidas? Não é admissivel que, em uma questão deste genero, nos preoccupemos primeiro que tudo com a idéa de formar um exemplo. A historia ahi está para provar que o supplicio de um regicida jamais deteve a mão de um regicida; ao contrario, porque é sobretudo a gloria do martyrio o que procuram os fanaticos, e dizem: "as idéas se regam com sangue" 
Por outro lado perdoal-os não tem, sob este ponto de vista, efficacia alguma: basta o caso de La Sahla para o demonstrar. A maior parte dos regicidas, interrogados, affirma que recomeçaria, si fosse o caso.

N'estas condições é conveniente nos collocarmos sobre o terreno puramente scientifico e julgar como sempre, não o crime mas o criminoso.

Ora, que nos ensina a sciencia sob este ponto de vista? Nos mostra, como acabamos de vêr, que os regicidas são desharmonicos ou degenerados hereditarios, de temperamento mystico que, desviados por um delirio politico ou religioso complicado por vezes de allucinações, se crêm chamados ao duplo papel de justiceiros e martyres, e, sob o imperio de uma obcessão á qual não são livres de resistir, chegam a atacar um grande da terra em nome de Deus ou da patria.

Ella, em uma palavra, nos mostra que taes individuos são anormaes, geralmente mathoïdes ou semi-loucos, e que, si se tornaram criminosos, foi unicamente porque eram doentes.

Assim é facil a conclusão a tirar. Quando o regicida é manifestamente delirante e allucinado, não ha hesitação possivel, o internamento n'um hospicio é a medida que se impõe. $E$ é isto justamente o que mais teme o regicida: semelhante tratamente quebra o seu orgulho, porque elle considera uma vergonha ser tratado como um louco, elle, o heróe e martyr.

Quanto aos outros regicidas, aos que LASchI chama regicidas por paixão e que, na realidade, são enfermos embora em gráo menor; quanto a estes, que são antes desequilibrados e seus actos anormaes, que mostram quão perigosos podem se tornar para a sociedade, a solução mais conforme aos dados da sciencia e ao interesse publico consistirá em collocal-os, pelo tempo necessario e com as garantias medico-judiciarias, em um desses asylos de alienados criminosos de que certos paizes são de a muito dotados, e que a grande maioria dos especialistas reclama na França 
e na Italia como um intermediario indispensavel entre a prisão e o asylo propriamento dito.

Assim cessariam para sempre estas controversias e estes conflictos que dividem, ha muitos annos, a sciencia e a justiça; controversias e conflictos que têm por unico resultado, n'um seculo como o nosso, de entregar ao ultimo supplicio um regicida alienado, ou lançal-o perpetuamente n'uma prisão em que elle dá ao mundo o triste espectaculo de um forçado chegado ao ultimo gráo da desmoralisação e da demencia.

Eis ahi, meus senhores, apontados os males a conjurar. Aos moços que agora para esta casa entram; aos que ainda aqui permanecerão por algum tempo, e aos que nos vão deixar eu direi: nunca vos esqueçaes da eterna verdade de que para os grandes males só os grandes remedios; a que o remedio supremo para tudo isso é o culto fervoroso do direito, d'essa entidade abstracta e pura que não é sómente a arte do bom, do justo e do equitativo; que não é simplesmente a pacificação do antagonismo das forças sociaes, mas que é tudo isso ao mesmo tempo, e ainda o sol refulgente que nos illumina a vida social e politica; a suprema bussola que nos orienta a rota no mare magnum da existencia collectiva.

Estudemos, pois, com ardor e paciencia. A Patria de vós tudo espera e a Republica tudo vos confiará! 